\title{
National Park Service Operational Leader AMK RANCH (UW-NPS RESEARCH CENTER)
}

\section{CATHIE JEAN $\downarrow$ NATIONAL PARK SERVICE $\downarrow$ GREATER YELlOWSTONE NETWORK}

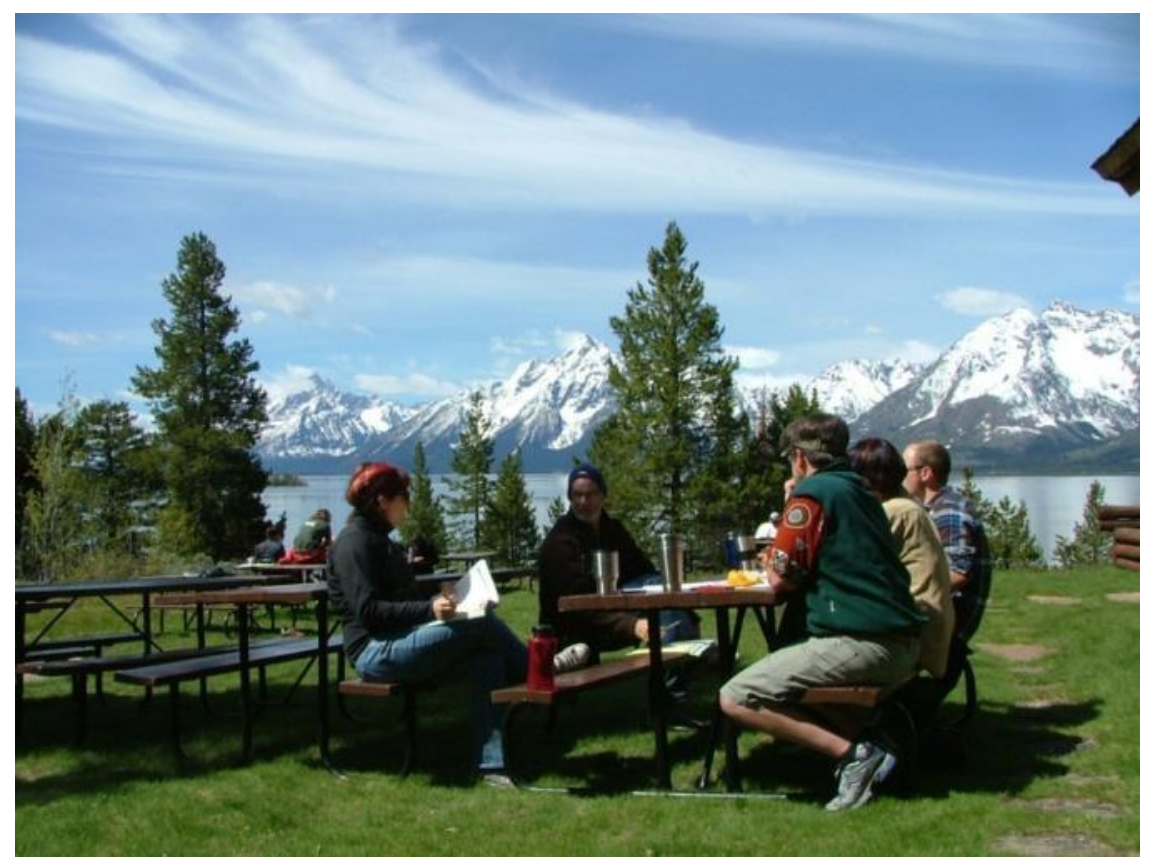

National Park Service inventory and monitoring staff at AMK Ranch in Grand Teton National Park (Photo credit: NPS Laura O'Gan).

\section{OPERATIONAL LEADERSHIP}

On May 30 and 31, 2012, a group of 18 National Park Service employees convened at AMK Ranch to learn the principles of Operation Leadership. Operational Leadership, at its core, is a systematic process that assists individuals in making informed decisions to reduce and manage risk in the workplace. Operational leadership is about each employee becoming a leader within his or her own job, taking responsibility for his or her own safety and the safety of coworkers, and learning to work effectively in a team environment. It pertains to every job skill and empowers employees to be assertive about their safety and the safety of their team.
The two-day course was facilitated by Patrick Hattaway and Reggie Treese of Grand Teton National Park, both of whom did a fantastic job introducing the group to the seven critical skills necessary to reduce the probably of human error.

Operational Leadership skills include:

\section{Leadership}

Not in the traditional sense, leadership here refers to individual and team leadership qualities. In the workplace each of us must be a leader in order to create a safer environment.

\section{Human Error and Accident Causation}


In order to reduce the probability of human error, we must first understand how and why human error occurs, and how human error leads to accidents.

\section{Mission Analysis}

Everything we do in life is a "mission;" as leaders we must be able to analyze each mission, assess its risks, mitigate those risks, and plan and act accordingly.

\section{Stress and Performance}

Once we begin the mission analysis process, we must be able to continually monitor our situation and be flexible to changing conditions. In order to do this, we must understand how stress, fatigue, and morale affect our performance.

\section{Situational Awareness}

Meeting mission demands and monitoring our mission success requires constant awareness of our surroundings, and the ability to recognize potential hazards.

\section{Decision Making}

The backbone of Operational Leadership is good decision making, and the fortitude to make those decisions and stand behind those who make them.

\section{Effective Communication and Assertiveness.}

Each of the first six skills requires team members to communicate effectively, and to be assertive about their involvement in the risk management process. Each employee is responsible for speaking up about potential hazards to the team.
The two-day course was organized by the Greater Yellowstone Inventory and Monitoring Network. Participants included a diverse mix of employees, many of which work for the Greater Yellowstone and Rocky Mountain I\&M networks. These networks conduct inventory and monitoring activities in national parks such as Glacier, Rocky Mountain, Great Sand Dunes, Yellowstone, and Grand Teton, as well as many smaller parks including Bighorn Canyon National Recreation Area, and Little Bighorn Battle and Florissant Fossil Beds National Monuments.

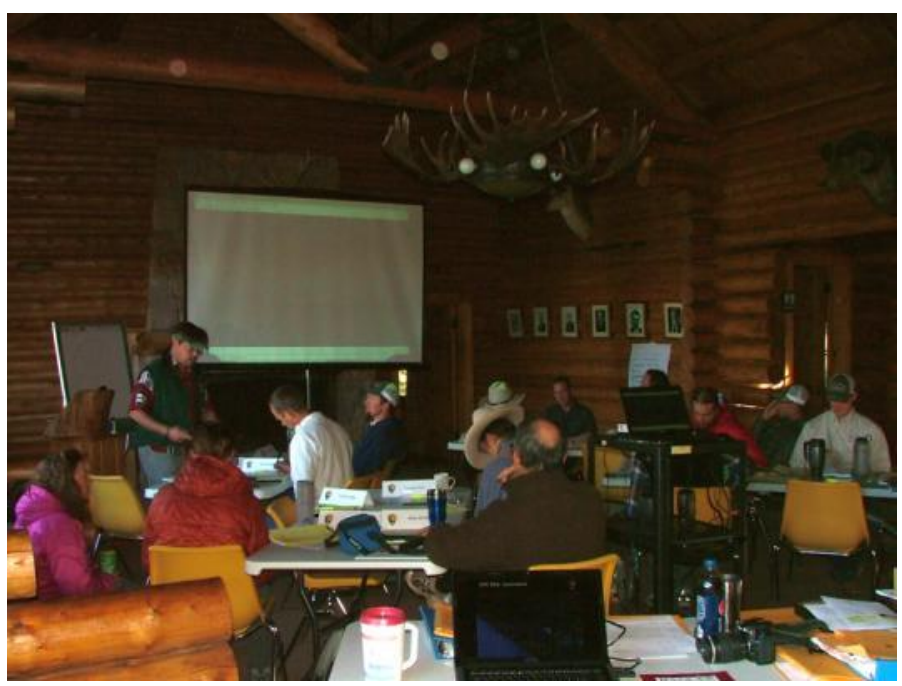

National Park Service employees at the Berol Lodge prepare for another lesson in Operational Leadership (Photo credit: NPS Laura O'Gan). 